\title{
Increased liver and lupus mortalities in 24-year follow-up of the Taiwanese people highly exposed to polychlorinated biphenyls and dibenzofurans
}

\author{
Pei-Chien Tsai ${ }^{\mathrm{a}, \mathrm{b}}$, Ying-Chin Ko ${ }^{\mathrm{c}}$, Wenya Huang ${ }^{\mathrm{d}}$, \\ Hsiao-Sheng Liu ${ }^{\mathrm{e}}$, Yueliang Leon Guo ${ }^{\mathrm{a}, \mathrm{f}, *}$ \\ a Department of Environmental and Occupational Health, National Cheng Kung University, Tainan 701, Taiwan \\ ${ }^{\mathrm{b}}$ Department of Basic Medical Sciences, National Cheng Kung University, Tainan 701, Taiwan \\ ${ }^{c}$ Division of Environmental Health and Occupational Medicine, National Health Research Institute, Zhunan 350, Taiwan \\ ${ }^{\mathrm{d}}$ Department of Medical Laboratory Science and Biotechnology, National Cheng Kung University, Tainan 701, Taiwan \\ ${ }^{\mathrm{e}}$ Department of Microbiology and Immunology, National Cheng Kung University, Tainan 701, Taiwan \\ ${ }^{\mathrm{f}}$ Department of Occupational and Environmental Medicine, \\ National Taiwan University (NTU) College of Medicine and NTU Hospital, Taipei 100, Taiwan
}

Received 20 June 2006; received in revised form 2 December 2006; accepted 6 December 2006

Available online 24 January 2007

\begin{abstract}
Background: A follow-up study was designed to compare the 24-year overall and disease-specific mortality in Yucheng people who were highly exposed to polychlorinated biphenyls/dibenzofurans (PCBs/PCDFs) to that in the background population in Taiwan. In 1979, the Yucheng (oil-disease in Chinese) incident occurred in central Taiwan involving approximately 2000 victims due to ingestion of rice oil contaminated with PCBs/PCDFs. Long-term follow-up of these people has been continued for 24 years. Methods: Standardized mortality ratios were calculated using the Taiwan population as comparison group. Overall and diseasespecific mortality was compared between Yucheng and background populations.

Results: Mortality from chronic liver disease and cirrhoses was increased in the Yucheng men, but not in women, in the early period after exposure. Cancer mortality was not increased in the Yucheng population up to 24 years after exposure. SLE in females was highly increased in the later period after PCB/PCDF exposure. Mortality from disease in any other organ system was not significantly different between Yucheng and background populations.

Conclusions: The study provided a long-term mortality picture after the Taiwanese PCB/PCDF exposure incident. In addition to reconfirming the increase in liver mortality, we found high mortality of SLE among exposed population. This finding highlights the importance of further investigating the immunological effects associated with PCB/PCDF exposure.
\end{abstract}

(C) 2006 Elsevier B.V. All rights reserved.

Keywords: Systemic lupus erythematosus; Polychlorinated biphenyls; Polychlorinated dibenzofurans; Liver disease; Standardized mortality ratio

\footnotetext{
* Corresponding author. Department of Environmental and Occupational Medicine, National Taiwan University College of Medicine, Rm. 339, Syujhou Road, Taipei 100, Taiwan. Tel.: +886 922557708; fax: +886233228216.

E-mail address: leonguo@ha.mc.ntu.edu.tw (Y.L. Guo).
} 


\section{Introduction}

Polychlorinated dibenzodioxins (PCDDs), polychlorinated dibenzofurans (PCDFs), and polychlorinated biphenyls (PCBs) are ubiquitous environmental pollutants found in many environmental media, as well as biological samples from wildlife and humans (Anderson, 1989). PCBs became recognized as potentially harmful environmental contaminants in the 1970s, and their use and manufacture were prohibited in many countries.

Since dioxin-like chemicals were strong animal carcinogens, mortality investigations on PCBs and dioxin-like chemicals have relatively emphasized on cancer outcomes until recent years. Published follow-up studies of workers exposed to PCBs through inhalational or dermal routes showed inconsistent results with elevated mortality rates for brain cancer (Sinks et al., 1992; Kimbrough et al., 2003; Ruder et al., 2006), gastrointestinal cancer (Bertazzi et al., 1987; Tironi et al., 1996; Kimbrough et al., 2003; Prince et al., 2006), malignant melanoma (Sinks et al., 1992; Kimbrough et al., 2003; Ruder et al., 2006), cancer of the biliary tract, liver and gallbladder (Brown and Jones, 1981; Brown, 1987; Kimbrough et al., 2003; Gustavsson et al., 1986; Gustavsson and Hogstedt, 1997; Prince et al., 2006), cancer of the hematopoietic system (Bertazzi et al., 1987; Kimbrough et al., 2003; Gustavsson et al., 1986; Gustavsson and Hogstedt, 1997) and prostate cancer (Prince et al., 2006; Charles et al., 2003). Cardiovascular diseases, diabetes, and autoimmune diseases were not found increased in most of the above studies.

Follow-up of occupational cohorts exposure to PCDD/PCDF and Ranch Hand cohort exposed to Agent Orange contaminated with 2,3,7,8-tetrachlorodibenzo-p-dioxin (TCDD) showed increased cancer mortality (Fingerhut et al., 1991; Steenland et al., 1999; Flesch-Janys et al., 1998; Hooiveld et al., 1998; Ott and Zober, 1996; Ketchum and Michalek, 2005). Significant cause-specific cancer mortalities were documented including rectum cancer (Flesch-Janys et al., 1998), larynx cancer (Steenland et al., 1999), bladder cancer (Steenland et al., 1999), respiratory (Fingerhut et al., 1991; Flesch-Janys et al., 1998; Hooiveld et al., 1998; Ott and Zober, 1996), soft tissue sarcoma (Fingerhut et al., 1991; Saracci et al., 1991), and lymphatic and hematopoietic cancer (Flesch-Janys et al., 1998; Steenland et al., 1999). Although Seveso cohort exposed to TCDD failed to exhibit significant increase of all cancer mortality (Bertazzi et al., 2001), lymphatic and hematopoeitic cancers were found increased, as well as cancers in rectum and lung among men. In the Japanese
Yusho ("oil-disease" in Japanese) population exposed to PCBs and PCDFs, increased liver cancer mortality in both sexes and lung cancer mortality in men were reported at the 15-year follow-up. Mortality of circulatory diseases was increased in Ranch Hand cohort (Ketchum and Michalek, 2005). Deaths due to diabetes and chronic obstructive pulmonary disease were found increased in Seveso cohort (Bertazzi et al., 2001). Mortality caused by chronic liver disease was found increased in Japanese Yusho cohort at a non-statistically significant level (Ikeda et al., 1987).

In 1979, over 2000 people in central Taiwan ingested cooking rice oil contaminated with $\mathrm{PCBs} / \mathrm{PCDFs}$ (Hsu et al., 1985). The victims were estimated to consume an average of $1 \mathrm{~g}$ of PCBs and $3.8 \mathrm{mg}$ of PCDFs totally during an average of 9 months of exposure to the contaminated oil (Lan et al., 1981). The structure of PCDFs is similar to TCDD, a known potent carcinogen (Voogt and Brinkman, 1989). Such consumption resulted in median serum levels at the order of 10-40 times higher than background for PCBs and 10,000 times higher for penta-CDF (Svensson et al., 1991). By 1983, a Yucheng ("oil-disease" in Chinese) registry was set up and maintained by the Taiwan Provincial Department of Health including 1991 directly exposed subjects, and 70 children exposed in utero (Hsu et al., 1985).

We began following he Yucheng cohort and studied mortality related to exposure in 1992. Increased mortality due to chronic liver disease and cirrhosis was found 13 years after exposure, but not increase in cancer mortality (Yu et al., 1997). This study extends the follow-up period and examines the mortality in the Yucheng cohort 24 years after exposure to PCBs and PCDFs. Since we have more person-years of follow-up, we are able to stratify the Yucheng population into males and females, and also looked into different periods after the exposure, i.e., $0-7,8-15$, and 16-23 years.

\section{Materials and methods}

The follow-up study of mortality status has been approved by the Institutional Review Board of The National Cheng Kung University. We obtained the Yucheng Registry previously (Yu et al., 1997). Among the 1991 in the list, 154 did not appear in the registration office records, or did not have an address, and thus could not be traced further. These individuals were excluded from the first study of mortality in 1992 (Yu et al., 1997). In this study, we were able to obtain the checking system for the national identification (ID) numbers. The last digit of the national ID was a build-in checking code. Among those Yucheng individuals whose national IDs 
Table 1

Age distribution in 1980 and vital status of 2003 in Yucheng cohort

\begin{tabular}{lcl}
\hline Subject no. & Males $(n=841)$ & Females $(n=982)$ \\
\hline Age in 1979 & & \\
$0-19$ & $376(45 \%)$ & $457(46 \%)$ \\
$20-39$ & $252(30 \%)$ & $345(35 \%)$ \\
$40-59$ & $191(23 \%)$ & $146(15 \%)$ \\
$60+$ & $22(2 \%)$ & $34(4 \%)$ \\
& & \\
Vital status of December 31, 2003 & $896(91 \%)$ \\
Alive & $712(85 \%)$ & $86(9 \%)$ \\
Deceased & $129(15 \%)$ & 23,611 \\
Person-years of follow-up & 19,708 & \\
\hline
\end{tabular}

were in the registry, 14 did not qualify the checking mechanism and were excluded from the follow-up for mortality. For the 1823 Yucheng subjects whose national ID was presumably correct, these IDs were compared with the national death registry to determine mortality status, cause of death, and among deceased, the date of death. In Taiwan, it is mandatory to report deaths within 1 month to the registration office of resided village, town, or city precinct. Such reporting of death in Taiwan is believed to be complete. Cause of death was coded according to the ninth revision of the International Classification of Diseases (ICD-9). Among the 1823
Yucheng subjects, 215 had died between January 1, 1980 and December 31, 2003.

For confirmation of cause of death in deceased cases, we acquired a copy of the death certificate from the house registration office and abstracted information on date, place, and cause of death. The household registration offices kept forwarding addresses indefinitely for those who had moved. If a deceased subject had previously moved, we went to the registration office at the forwarding address until we found a current record. A copy of the death certificate was then obtained from the most recent household registration office.

The overall and cause-specific mortality of the exposed group were compared to those of the Taiwan general population. Each study subject contributed person-time of observation from January 1, 1980 to the date of the end of follow-up (December 31, 2003) or through the date of death. We elected not to include the year of 1979, because those who died in 1979 might not have been included in the registry from the very beginning and this could potentially introduce bias into this study.

The population database and mortality registry in Taiwan were obtained from the Department of Statistics and the Ministry of Interior and Department of Health,

Table 2

Observed and expected numbers of deaths and standardized mortality ratio for overall and cause-specific deaths among 1823 Yucheng subjects, 1980-2003

\begin{tabular}{|c|c|c|c|c|c|c|c|c|c|}
\hline \multirow[t]{2}{*}{ Cause of death (ICD-9 codes*) } & \multicolumn{3}{|c|}{ Males } & \multicolumn{3}{|c|}{ Females } & \multicolumn{3}{|c|}{ Total } \\
\hline & obs & $\exp$ & $\operatorname{SMR}(95 \% \mathrm{CI})^{\mathrm{a}}$ & obs & $\exp$ & $\operatorname{SMR}(95 \% \mathrm{CI})^{\mathrm{a}}$ & obs & $\exp$ & $\operatorname{SMR}(95 \% \mathrm{CI})^{\mathrm{a}}$ \\
\hline All causes (001-999) & 129 & 130.4 & $1.0(0.8-1.2)$ & 86 & 82.6 & $1.0(0.8-1.3)$ & 215 & 220.4 & $1.0(0.8-1.1)$ \\
\hline Tuberculosis $(011)$ & 6 & 2.6 & $2.3(0.8-5.0)$ & 0 & 0.8 & - & 6 & 3.5 & $1.7(0.6-3.7)$ \\
\hline Malignant neoplasms (140-208) & 29 & 32.3 & $0.9(0.6-1.3)$ & 12 & 19.6 & $0.7(0.3-1.1)$ & 41 & 52.8 & $0.8(0.6-1.1)$ \\
\hline Nasopharyngeal (147) & 3 & 1.3 & $2.3(0.5-6.8)$ & 0 & 0.5 & - & 3 & 1.8 & $1.6(0.3-4.7)$ \\
\hline Liver and intrahepatic bile duct (155) & 4 & 8.2 & $0.5(0.1-1.2)$ & 4 & 2.5 & $1.6(0.4-4.1)$ & 8 & 11.1 & $0.7(0.3-1.4)$ \\
\hline Lung (162) & 7 & 6.7 & $1.1(0.4-2.2)$ & 1 & 3.0 & $0.3(0.0-1.9)$ & 8 & 9.8 & $0.8(0.4-1.6)$ \\
\hline Lymphatic and hemopoietic (200-208) & 4 & 1.7 & $2.3(0.6-6.0)$ & 0 & 1.2 & - & 4 & 3.0 & $1.3(0.4-3.4)$ \\
\hline Circulatory system (390-459) & 28 & 30.8 & $0.9(0.6-1.3)$ & 26 & 22.2 & $1.2(0.8-1.7)$ & 54 & 53.9 & $1.0(0.8-1.3)$ \\
\hline Respiratory system (460-519) & 6 & 9.8 & $0.6(0.2-1.3)$ & 6 & 5.6 & $1.2(0.4-2.6)$ & 12 & 15.0 & $0.8(0.4-1.4)$ \\
\hline Digestive system (520-579) & 20 & 11.8 & $1.7(1.0-2.6)$ & 7 & 5.1 & $1.4(0.6-2.9)$ & 27 & 17.7 & $1.5(1.0-2.2)$ \\
\hline Chronic liver disease and cirrhosis (571) & 15 & 6.8 & $2.2(1.2-3.6)$ & 2 & 2.4 & $0.8(0.1-3.0)$ & 17 & 9.8 & $1.7(1.0-2.8)$ \\
\hline Genitourinary system (580-629) & 4 & 3.7 & $1.1(0.3-2.7)$ & 5 & 3.6 & $1.4(0.5-3.2)$ & 9 & 7.4 & $1.2(0.6-2.3)$ \\
\hline Musculoskeletal System (710-739) & 0 & 0.4 & - & 6 & 0.7 & $8.9(3.2-19.3)$ & 6 & 1.0 & $5.9(2.1-12.7)$ \\
\hline Systemic lupus erythematosus (710.0) & 0 & 0.1 & - & 5 & 0.3 & $14.7(4.7-34.4)$ & 5 & 0.4 & $13.8(4.4-32.2)$ \\
\hline $\begin{array}{l}\text { Endocrine, metabolic disease, and immunity } \\
\text { disorders }(240-279)\end{array}$ & 4 & 5.9 & $0.7(0.2-1.8)$ & 8 & 6.9 & $1.2(0.5-2.3)$ & 12 & 12.8 & $0.9(0.5-1.6)$ \\
\hline Diabetes mellitus (250) & 1 & 5.4 & $0.2(0.0-1.0)$ & 6 & 6.5 & $0.9(0.3-2.0)$ & 7 & 12.0 & $0.6(0.2-1.2)$ \\
\hline Mental and psychoneurotic disorders (290-319) & 1 & 0.6 & $1.8(0.0-10.0)$ & 0 & 0.3 & - & 1 & 0.9 & $1.1(0.0-6.2)$ \\
\hline All accidents and external (E800-E999) & 18 & 21.2 & $0.9(0.5-1.3)$ & 7 & 8.7 & $0.8(0.3-1.7)$ & 25 & 31.8 & $0.8(0.5-1.2)$ \\
\hline
\end{tabular}

*ICD-9, International Classification of Diseases, ninth revision; obs: observed no; exp: expected no.; CI=confidence interval.

Bolded text indicates that the observed/expected ratio is statistically different from one.

a The calculation of standardized mortality ratio (SMR) were as follows: the number of observed cause-specific deaths was divided by the number of expected cause-specific deaths between 1980 to 2003. 
Table 3

Characteristics of the five SLE patients in Yucheng exposure groups

\begin{tabular}{llclll}
\hline Subject $^{\text {a }}$ & Age/year of death & PCB level $(\mathrm{ppb}) /$ year of measurement & Country & Occupation & Death certificate \\
\hline 1 & $27 / 1989$ & $61 / 1985$ & Nantou & None & SLE/pneumonia \\
2 & $33 / 1994$ & $15 / 1981$ & Taichung & Housewife & SLE/pneumonia/septicemia \\
3 & $39 / 1996$ & $162 / 1980$ & Changhua & None & SLE/septicemia/brain edema \\
4 & $40 / 1997$ & $92 / 1980$ & Changhua & Farmer & SLE \\
5 & $44 / 1999$ & $75 / 1982$ & Changhua & Manufacture umbrella & SLE \\
\hline
\end{tabular}

${ }^{\text {a }}$ All SLE subjects were females.

b Background PCB level: 1.7 ppb.

respectively. Totally, 2,085,218 deaths were recorded by the mortality registry in Taiwan from 1980 to 2003.

We used an age-modified method to calculate standardized mortality ratio (SMR). The person-years at risk for all subjects were combined into gender, 5-year age, and 1-year calendar time specific groups. The accumulated person-years were then multiplied by the gender, age, calendar time, and cause-specific Taiwan mortality rates to yield the expected numbers of causespecific deaths. The number of observed cause-specific deaths was then divided by the number of expected cause-specific deaths to yield the SMR. The 95\% confidence intervals around the SMRs were estimated based on Poisson distribution (Rothman and Boice, 1979). Mortality data also were analyzed separated by gender and latency periods (i.e., $0-7$ years, $8-15$ years, and 16-23 years) since first exposure ("latency").

\section{Results}

\subsection{Subjects}

A total of 1823 Yucheng subjects with 43,319 person-years are at risk from the time of first exposure to PCBs to date of death or the last date of each study period. The age, gender, and vital status distribution of the exposed subjects are shown in Table 1. Two hundred fifteen subjects had died between January 1, 1980 and December 31, 2003.

\subsection{SMR, overall and by gender}

Table 2 shows results for the all cause and causespecific mortality. All cause mortality was not different from that in the Taiwan general population. There was a

Table 4

Observed and expected numbers of deaths, SMR, and 95\% confidence interval, by cause of death and years since first exposure in the Yucheng population exposed to PCBs/PCDFs from 1980 to 2003

\begin{tabular}{|c|c|c|c|c|c|c|c|c|c|}
\hline \multirow[t]{3}{*}{ Cause of death (ICD-9 codes) } & \multicolumn{9}{|c|}{ No. of years since first exposure (A.D.) } \\
\hline & \multicolumn{3}{|c|}{$0-7(1980-1987)$} & \multicolumn{3}{|c|}{$8-15(1988-1995)$} & \multicolumn{3}{|c|}{$16-23(1996-2003)$} \\
\hline & obs & $\exp$ & $\operatorname{SMR}(95 \% \mathrm{CI})$ & obs & $\exp$ & SMR $(95 \% \mathrm{CI})$ & obs & $\exp$ & SMR $(95 \% \mathrm{CI})$ \\
\hline All causes & 46 & 48.8 & $1.0(0.7-1.3)$ & 70 & 72.7 & $1.0(0.8-1.2)$ & 99 & 98.8 & $1.0(0.8-1.2)$ \\
\hline Tuberculosis (011) & 0 & 1.2 & - & 2 & 1.2 & $1.7(0.2-6.1)$ & 4 & 1.1 & $3.6(1.0-9.1)$ \\
\hline Malignant neoplasms (140-208) & 4 & 10.1 & $0.4(0.1-1.0)$ & 7 & 16.0 & $0.4(0.2-0.9)$ & 30 & 26.7 & $1.1(0.8-1.6)$ \\
\hline Nasopharyngeal (147) & 0 & 0.5 & - & 1 & 0.6 & $1.6(0.0-8.6)$ & 2 & 0.7 & $2.7(0.3-9.6)$ \\
\hline Liver and intrahepatic bile duct (155) & 2 & 2.2 & $0.9(0.1-3.3)$ & 2 & 3.5 & $0.6(0.1-2.1)$ & 4 & 5.5 & $0.7(0.2-1.9)$ \\
\hline Lung (162) & 1 & 1.6 & $0.6(0.0-3.5)$ & 1 & 2.9 & $0.3(0.0-1.9)$ & 6 & 5.3 & $1.1(0.4-2.5)$ \\
\hline Lymphatic and hemopoietic (200-208) & 0 & 0.7 & - & 2 & 0.9 & $2.2(0.2-8.0)$ & 2 & 1.4 & $1.4(0.2-5.2)$ \\
\hline Circulatory system (390-459) & 18 & 13.3 & $1.4(0.8-2.1)$ & 19 & 19.0 & $1.0(0.6-1.6)$ & 17 & 21.6 & $0.8(0.5-1.3)$ \\
\hline Respiratory system $(460-519)$ & 0 & 2.4 & - & 8 & 4.6 & $1.7(0.8-3.4)$ & 4 & 8.1 & $0.5(0.1-1.3)$ \\
\hline Digestive system (520-579) & 11 & 3.8 & $2.9(1.4-5.2)$ & 5 & 5.7 & $0.9(0.3-2.0)$ & 11 & 8.2 & $1.3(0.7-2.4)$ \\
\hline Chronic liver disease and cirrhosis (571) & 8 & 2.2 & $3.7(1.6-7.2)$ & 3 & 3.1 & $1.0(0.2-2.9)$ & 6 & 4.5 & $1.4(0.5-2.9)$ \\
\hline Genitourinary system (580-629) & 2 & 1.4 & $1.4(0.2-5.2)$ & 4 & 2.1 & $1.9(0.5-4.8)$ & 3 & 3.9 & $0.8(0.2-2.3)$ \\
\hline Musculoskeletal System (710-739) & 0 & 0.3 & - & 3 & 0.3 & $10.1(2.0-29.6)$ & 3 & 0.5 & $6.3(1.3-18.3)$ \\
\hline SLE (710.0) & 0 & 0.1 & - & 2 & 0.1 & $19.8(2.2-71.3)$ & 3 & 0.2 & $18.9(3.8-55.2)$ \\
\hline Endocrine, metabolic and immunity disorders (240-279) & 1 & 1.5 & $0.7(0.0-3.8)$ & 2 & 3.8 & $0.5(0.1-1.9)$ & 9 & 7.6 & $1.2(0.5-2.3)$ \\
\hline Diabetes mellitus (250) & 1 & 1.3 & $0.8(0.0-4.2)$ & 1 & 3.5 & $0.3(0.0-1.6)$ & 5 & 7.1 & $0.7(0.2-1.6)$ \\
\hline Mental and psychoneurotic disorders (290-319) & 0 & 0.2 & - & 1 & 0.3 & $3.6(0.1-20.0)$ & 0 & 0.4 & - \\
\hline All accidents and external (E800-E999) & 6 & 10.3 & $0.6(0.2-1.3)$ & 8 & 11.6 & $0.7(0.3-1.4)$ & 11 & 9.9 & $1.1(0.6-2.0)$ \\
\hline
\end{tabular}

Bolded text indicates that the observed/expected ratio is statistically different from one. 
significant elevation of mortality for diseases of digestive system (SMR: $1.5,95 \%$ CI 1.0-2.2) and twothirds of these deaths were due to chronic liver disease and cirrhosis (SMR: 1.7, 95\% CI 1.0-2.8). Such increase in mortality was most prominent in men (SMR: 2.2, 95\% CI: 1.2-3.6). Overall mortality from neoplasms was not different from background population. In men, the SMR of nasopharyngeal cancer and lymphatic/hematopoietic cancers were approximately two fold of the general population, but the increase was not statistically significant. Mortality of systemic lupus erythematosus (SLE) was increased significantly in Yucheng females (five deaths, SMR $=14.7,95 \% \mathrm{CI}$ : 4.7-34.4). The death certificate of these five women with SLE was obtained from each responsible household registration office. Causes of deaths were confirmed to be SLE. In addition, complications of SLE contributed to direct causes of death among these individuals, including pneumonia, septicemia, and brain edema. Blood levels of PCBs in those with SLE were previously determined to be between 15 and 162 ppb by the Provincial Department of Health in 1980-85. The year of death from SLE ranged from 10 to 20 years after the exposure, with median of 17 years (Table 3 ).

\subsection{SMR by latency periods}

The mortality results by latency periods are shown in Table 4. The SMR of "digestive system", and "chronic liver disease and cirrhosis" was elevated 0-7 years after the incident, with ratio estimates 2.9 (95\% CI: 1.4-5.2) and 3.7 (95\% CI: 1.6-7.2), respectively. Such increase in SMR was not seen during the 2nd and the 3rd eightyear periods. SLE was highly increased in the later two periods, with SMR of SLE as high as twenty fold compared to the Taiwan general population. Tuberculosis was significantly increased in the latest observation period (16-23 years after the incident).

\section{Discussion}

In this study, long-term follow-up of mortality among the population exposed to PCBs/PCDFs after Taiwan "Yucheng" incident was reported. Mortality of chronic liver disease and cirrhoses was found increased in early period after exposure in exposed men, but not in women. The rare autoimmune disease-SLE was highly increased in women during both later periods $(8-15$, and 16-23 years) after PCBs/PCDFs exposure as compared to the Taiwan general population. Cancer mortality was not increased in the Yucheng population up to 24 years after exposure.
We have chosen the period of 8 years mainly to determine whether early and later causes of deaths among Yucheng victims were different. We used 8 years (tertiles) because using quartiles (6 years) or quintile would cause the person-years in each period to be rather small. However, dividing the 24 years of follow-up into quartiles or quintiles would not have changed the findings of early liver mortality and later SLE mortality.

Our finding that mortality due to chronic liver disease and cirrhosis were increased during the first latency period was consistent with previous studies on the Yucheng population (Yu et al., 1997). Such increase in liver disease mortality was reported in Japanese people accidentally exposed to $\mathrm{PCBs} / \mathrm{PCDF}$ in a similar poisoning event (Yusho incident) in 1968 (Ikeda et al., 1987). Although mortality studies don't allow for detailed investigation of mechanisms of such increase in liver mortality, abnormal liver function was documented among Yucheng subjects after the exposure (Lü and Wong, 1984). In addition, urinary excretion of uroporphyrin was approximately tripled (Chang et al., 1980). Certain levels of liver damage could have contributed to the increased liver mortality, likely among those with existing liver conditions. Although the background carrier rate of hepatitis B was high, there is no reason to suspect that Yucheng victims had higher carrier rate than the background population. The similar liver mortality rates during the 2 nd and the 3 rd eightyear periods suggested similar carrier rates among Yucheng victims as the background population in Taiwan.

A 15-year follow-up of 1761 "Yusho" subjects showed increases in liver cancer mortality in both sexes and lung cancer mortality in men (Ikeda et al., 1987). Among Seveso residents exposed to TCDD, lymphatic and hematopoietic neoplasms, as well as rectal and lung cancers were significantly increased 20 years after TCDD exposure (Bertazzi et al., 2001). However, among Yucheng individuals, mortality from all malignant neoplasms was not different from the general population, nor were liver, lung, or lymphatic/ hematopoietic cancers.

Among the Yucheng population, an unexpected finding was a highly increased mortality of SLE in exposed women starting 10 years after the exposure. During both the 2nd and 3rd eight-year periods, the mortality of SLE was more than 20 fold higher than the background rates. SLE is a rare disease in Taiwan, with a yearly mortality rate of $9.3 / 1,000,000$, mainly involving females. Therefore, two deaths during the 2nd eightyear period, and three during the 3 rd period were unlikely to be caused by chance. 
The etiology for SLE is complex and likely involved multiple factors, including genetic predisposition, exposure to sex hormones, estrogenic compounds, and chemical/physical factors. Known chemical/physical factors include aromatic amines, hydrazine, tobacco smoke, hair dyes, ultraviolet light, and drugs such as procainamide, hydralazine, chlorpromazine, isoniazid, phenytoin, and penicillamine. PCBs and PCDFs have not previously been associated with SLE occurrence. Sex hormones may modify susceptibility and clinical expression of SLE (Casoli et al., 1997; Ostensen, 1999). Therefore, status of estrogenicity seems to play an important role in SLE occurrence. PCBs/PCDFs/ PCDDs are known to disrupt endocrine and reproductive systems. TCDD reduced serum estradiol (E2) in macaque monkeys (Guo et al., 1999) but increased estrogen receptor (ER)- $\beta$ expression in rat granulosa cells (Dasmahapatra et al., 2001). In addition, exposure to these chemicals is known to cause immunological effects. TCDD unregulated production of type 2 helper (Th2) cytokine, interleukin-4 (IL-4). An occupational study in German workers, higher PCB 138 serum concentration was associated with higher IL-4 (Daniel et al., 2001). IL-4 was also enhanced in Vietnam War veterans exposed to Agent Orange, which was in turn contaminated with TCDD (Kim, 2003). It can be postulated that TCDD-induced $\mathrm{Th} 2$ response enhances B cell antibody secretion, and initiates the autoimmune response seen in SLE. Although an accidental finding, the increased SLE after heavy exposure to PCBs and PCDFs might bring significant insight into the study of the etiology in SLE.

In conclusion, the 24-year follow-up of the mortality in the Yucheng population found an early increase in liver mortality in men, and a delayed increase in SLE mortality in women. Further investigation is warranted to examine the mechanisms of SLE after PCBs/PCDFs exposure, as well as other autoimmune disease among exposed people.

\section{References}

Anderson HA. General population exposure to environmental concentration of halogenated biphenyls. In: Kimbrough RD, Hansen AA, editors. Halogenated Biphenyls, Terphenyls, Naphthalenes, Dibenzodioxinx and Related Products. Amsterdam: Elsevier; 1989. p. 325-44.

Bertazzi PA, Riboldi L, Pesatori A, Radice L, Zocchetti C. Cancer mortality of capacitor manufacturing workers. Am J Ind Med 1987;11:165-76.

Bertazzi PA, Consonni D, Bachetti S, Rubagotti M, Baccarelli A, Zocchetti C, et al. Health effects of dioxin exposure: a 20-year mortality study. Am J Epidemiol 2001;153:1031-44.
Brown DP. Mortality of workers exposed to polychlorinated biphenylsan update. Arch Environ Health 1987;42:333-9.

Brown DP, Jones M. Mortality and industrial hygiene study of workers exposed to polychlorinated biphenyls. Arch Environ Health 1981;36:120-9.

Casoli P, Tumiati B, La Sala G. Fatal exacerbation of systemic lupus erythematosus after induction of ovulation. J Rheumatol 1997;24: 1639-40.

Chang KJ, Lu FJ, Tung FC, Lee TP. Studies on patients with polychlorinated biphenyl poisoning: 2 . Determination of urinary coproporphyrin, uroporphyrin, $\Delta$-aminolevulinic acid and porphobilinogen. Res Commun Chem Pathol Pharmacol 1980;30: 547-54.

Charles LE, Loomis D, Shy CM, Newman B, Millikan R, NylanderFrench LA, et al. Electromagnetic fields, polychlorinated biphenyls, and prostate cancer mortality in electric utility workers. Am J Epidemiol 2003;157:683-91.

Daniel V, Huber W, Bauer K, Suesal C, Conradt C, Opelz G. Associations of blood levels of PCB, HCHS, and HCB with numbers of lymphocyte subpopulations, in vitro lymphocyte response, plasma cytokine levels, and immunoglobulin. Environ Health Perspect 2001;109:173-8.

Dasmahapatra AK, Wimpee BA, Trewin AL, Hutz RJ. 2,3,7,8Tetrachlorodibenzo-p-dioxin increases steady-state estrogen receptor-beta mRNA levels after CYP1A1 and CYP1B1 induction in rat granulosa cells in vitro. Mol Cell Endocrinol 2001;182:39-48.

Fingerhut MA, Halperin WE, Marlow DA, Piacitelli LA, Honchar PA, Sweeney MH, et al. Cancer mortality in workers exposed to 2,3,7,8tetrachlorodibenzo-p-dioxin. N Engl J Med 1991;324:212-8.

Flesch-Janys D, Steindorf K, Gurn P, Becher H. Estimation of the cumulated exposure to polychlorinated dibenzo-p-dioxins/furans and standardized mortality ratio analysis of cancer mortality by dose in an occupationally exposed cohort. Environ Health Perspect 1998;106:655-62.

Guo Y, Hendrickx AG, Overstreet JW, Dieter J, Stewart D, Tarantal $\mathrm{AF}$, et al. Endocrine biomarkers of early fetal loss in cynomolgus macaques (Macaca fascicularis) following exposure to dioxin. Biol Reprod 1999;60:707-13.

Gustavsson P, Hogstedt C. A cohort study of Swedish capacitor manufacturing workers exposed to polychlorinated biphenyls (PCBs). Am J Ind Med 1997;32:234-9.

Gustavsson P, Hogstedt C, Rappe C. Short-term mortality and cancer incidence in capacitor manufacturing workers exposed to polychlorinated biphenyls (PCBs). Am J Ind Med 1986;10:341-4.

Hooiveld M, Heederik DJ, Kogevinas M, Boffetta P, Needham LL, Patterson Jr DG, et al. Second follow-up of a Dutch cohort occupationally exposed to phenoxy herbicides, chlorophenols, and contaminants. Am J Epidemiol 1998;147:891-901.

Hsu ST, Ma CI, Hsu SK, Wu SS, Hsu NH, Yeh CC, et al. Discovery and epidemiology of PCB poisoning in Taiwan: a four-year followup. Environ Health Perspect 1985;59:5-10.

Ikeda M, Kuratsune M, Nakamura Y, Hirohata T. A cohort study on mortality of Yusho patients - a preliminary report. Fukuoka Acta Med 1987;78:297-300.

Ketchum NS, Michalek JE. Postservice mortality of Air Force veterans occupationally exposed to herbicides during the Vietnam War: 20year follow-up results. Mil Med 2005;170:406-13.

Kim HA. Immunotoxicological effects of Agent Orange exposure to the Vietnam War Korean veterans. Ind Health 2003;41:158-66.

Kimbrough RD, Doemland ML, Mandel JS. A mortality update of male and female capacitor workers exposed to polychlorinated biphenyls. J Occup Environ Med 2003;45:271-82. 
Lan CF, Chen PH, Shieh LL, Chen YH. An epidemiological study on polychlorinated biphenyls poisoning in Taichung area. Clin Med 1981;7:96-100.

Lü YC, Wong PN. Dermatological, medical, and laboratory findings of patients in Taiwan and their treatments. Am J Ind Med 1984;5: 81-115.

Ostensen M. Sex hormones and pregnancy in rheumatoid arthritis and systemic lupus erythematosus. Ann N Y Acad Sci 1999;876:131-43.

Ott MG, Zober A. Cause specific mortality and cancer incidence among employees exposed to 2,3,7,8-TCDD after a 1953 reactor accident. Occup Environ Med 1996;53:606-12.

Prince MM, Ruder AM, Hein MJ, Waters MA, Whelan EA, Nilsen N, et al. Mortality and exposure response among 14,458 electrical capacitor manufacturing workers exposed to polychlorinated biphenyls (PCBs). Environ Health Perspect 2006;114:1508-14.

Rothman KJ, Boice Jr JD. Epidemiologic Analysis with a Programmable Calculator. Washington, DC: USDHEW, NIH; 1979.

Ruder AM, Hein MJ, Nilsen N, Waters MA, Laber P, Davis-King K, et al. Mortality among workers exposed to polychlorinated biphenyls (PCBs) in an electrical capacitor manufacturing plant in Indiana: an update. Environ Health Perspect 2006;114:18-23.

Saracci R, Kogevinas M, Bertazzi PA, Bueno de Mesquita BH, Coggon D, Green LM, et al. Cancer mortality in workers exposed to chlorophenoxy herbicides and chlorophenols. Lancet 1991;338: 1027-32.

Sinks T, Steele G, Smith AB, Watkins K, Shults RA. Mortality among workers exposed to polychlorinated biphenyls. Am J Epidemiol 1992;136:389-98.

Steenland K, Piacitelli L, Deddens J, Fingerhut M, Chang LI. Cancer, heart disease, and diabetes in workers exposed to 2,3,7,8tetrachlorodibenzo-p-dioxin. J Natl Cancer Inst 1999;91:779-86.

Svensson BG, Nilsson A, Hansson M, Rappe C, Åkesson B, Skerfving $\mathrm{S}$. Exposure to dioxins and dibenzofurans through the consumption of fish. N Engl J Med 1991;324:8-12.

Tironi A, Pesatori A, Consonni D, Zocchetti C, Bertazzi PA. The mortality of female workers exposed to PCBs. Epidemiol Prev 1996;20:200-2.

Voogt PDE, Brinkman UAT. Production, properties and usage of polychlorinated biphenyls. In: Kimbrough RD, Jensen AA, editors. Halogenated Biphenyls, Terphenyls, Naphthalenes, Dibenzodioxins and Related Products. Amsterdam: Elsevier; 1989. p. 3-45.

Yu ML, Guo YL, Hsu CC, Rogan WJ. Increased mortality from chronic liver disease and cirrhosis 13 years after the Taiwan "Yucheng" ("oil disease") incident. Am J Ind Med 1997;31:172-5. 